\title{
S(+)-Flurbiprofen Shows Potent PGE 2 Inhibitory Activity in Inflammatory Cells, Superior Cell Transport Activity and Skin Permeability
}

\author{
Yoshihisa Toda ${ }^{*}$, Masanori Sugimoto ${ }^{1}$, Hiromi Endo', Miho Kamezawa ${ }^{2}$, \\ Ichimaro Yamada ${ }^{2}$, Shogo Kawabata ${ }^{3}$, Shinsuke Kaku1, Noboru Otsuka4, \\ Hideo Matsumoto ${ }^{5}$

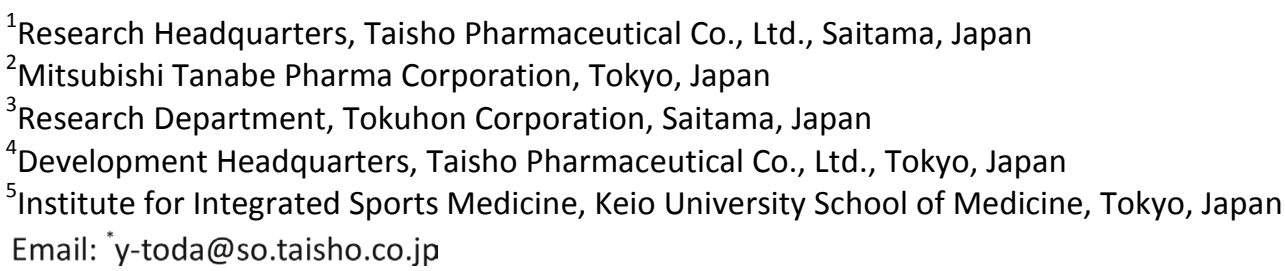

Received 13 July 2016; accepted 1 August 2016; published 4 August 2016

Copyright @ 2016 by authors and Scientific Research Publishing Inc.

This work is licensed under the Creative Commons Attribution International License (CC BY). http://creativecommons.org/licenses/by/4.0/

(c) (i) Open Access

\section{Abstract}

We developed a novel topical non-steroidal anti-inflammatory drug (NSAID)patch, S(+)-flurbiprofen plaster, (SFPP), containing S(+)-flurbiprofen (SFP), an enantiomer of flurbiprofen (FP). In a previous study conducted in an animal model, we showed good skin absorption and potent analgesic efficacy of SFPP. In this study, to examine the superior features, as an NSAID patch, of SFP as compared to FP and R(-)-flurbiprofen (RFP), we tested the stereospecificity of SFP actions on Prostaglandin $\mathrm{E}_{2}\left(\mathrm{PGE}_{2}\right)$ inhibition in rat inflammatory leukocytes and in the binding activity of the drug to cells, and also the in vitro skin permeability of the drug in the Yucatan micropig (YMP). SFP showed potent inhibitory activity on $\mathrm{PGE}_{2}$ production from peritoneal leukocytes stimulated with a bacterial suspension, as compared to RFP and FP. The half maximal (50\%) inhibitory concentration ( $\mathrm{IC}_{50}$ ) values were $14 \mathrm{nM}$ for SFP, $52 \mathrm{nM}$ for FP, and 17,000 $\mathrm{nM}$ for RFP. In the cell binding study, significant and rapid increase of SFP binding to polymorphonuclear leucocytes (PMNs) was observed at 5 min after incubation, eventually reaching a steady state. SFP showed significantly higher binding activity for the inflammatory leucocytes as compared to RFP, suggesting its superior transfer potency. The skin permeability profile of SFP, RFP and FP in the YMP model showed that the rank order of the cumulative amount of permeated compounds in the

\footnotetext{
${ }^{*}$ Corresponding author.
}

How to cite this paper: Toda, Y., Sugimoto, M., Endo, H., Kamezawa, M., Yamada, I., Kawabata, S., Kaku, S., Otsuka, N. and Matsumoto, H. (2016) S(+)-Flurbiprofen Shows Potent PGE 2 Inhibitory Activity in Inflammatory Cells, Superior Cell Transport Activity and Skin Permeability. Pharmacology \& Pharmacy, 7, 305-312. http://dx.doi.org/10.4236/pp.2016.78037 
skin was SFP > RFP > FP. The steady-state permeation rate (Flux) of SFP was significantly higher than that of FP $\left(4.89\right.$ and $1.55 \mathrm{mg} / \mathrm{cm}^{2} / \mathrm{h}$, respectively, $\left.p=0.0068\right)$, indicating the remarkably superior skin permeability of SFP. SFP exerted potent inhibitory activity on PGE $_{2}$ production and superior binding activity to the PMNs and skin permeability, as compared to FP and RFP. These results suggest that SFP possesses favorable characteristics for use as an active ingredient in the NSAID patch.

\section{Keywords}

NSAIDs, S(+)-Flurbiprofen, Cyclooxygenase, Skin Permeability

\section{Introduction}

Nonsteroidal anti-inflammatory drugs (NSAIDs) are widely used to treat chronic pain of musculoskeletal disorders such as rheumatoid arthritis (RA) and osteoarthritis (OA). It is generally assumed that NSAIDs exert their effects by specific inhibition of cyclooxygenase (COX) activity, thereby inhibiting the production of PGs, including $\mathrm{PGE}_{2}$, a major mediator of inflammatory pain [1]. However, chronic oral administration of NSAIDs is associated with the risk of a wide range of adverse effects, including gastrointestinal disorder. Therefore, the transdermal patch method that allows percutaneous absorption of NSAIDs has been used as an alternative [2]. Topical NSAIDs offer various advantages, including avoidance of hepatic first-pass metabolism, and a lower risk of gastrointestinal adverse effects [3]. However, one of the disadvantages of topical NSAIDs is poor absorption of the drug. Thus, we sought to develop a novel topical NSAID patch containing a potent NSAID that would show efficient absorption of the drug.

NSAIDs containing the 2-aryl propionic acid moiety, "profen”, including in ibuprofen, ketoprofen and flurbiprofen, are often prescribed for the treatment of articular diseases. In the past, the 2-aryl propionic acid NSAIDs were developed in the form of a racemic mixture, even though they occurred in enantiomeric pairs differing in the COX inhibitory activity [4] [5]. Flurbiprofen (FP) is a representative drug of the chiral NSAIDs of the 2arylpropionic acid class, and S(+)-flurbiprofen (SFP) has been shown to be a more potent COX inhibitor than the R(-)-flurbiprofen (RFP) enantiomer.

We previously showed that SFP inhibits human cyclooxygenase (COX)-1 and COX-2 more potently than other traditional NSAIDs. We showed in an experimental study using rats that the NSAID patch developed by us, the S-flurbiprofen plaster (SFPP), containing an (S)-enantiomer of flurbiprofen, was demonstrated to rapidly suppress inflammatory pain in the rat AIA model and also to show superior absorbability as compared to ketoprofen and loxoprofen patches [6]. Furthermore, we reported that the superior percutaneous absorption and greater tissue penetration of SFP into the human synovial tissue following application of SFPP in knee osteoarthritis (OA) patients [7].

In this study, to verify the favorable characteristics of SFP as the active ingredient of our newly developed NSAID patch, we tested the stereospecificity of the PGE $_{2}$ inhibitory activity of SFP in inflammatory leukocytes and its binding activity to inflammatory cells, and also the skin permeability of the drug in vitro in the Yucatan micropig (YMP) model, as compared to the corresponding activities of an FP racemic mixture and/or RFP enantiomer.

\section{Materials and Methods}

\subsection{Animals}

We used 5-week-old male Wistar rats (body weight; 112 - 153 g) for the pharmacology studies and 6-week-old male Wistar rats (body weight; 137 - $151 \mathrm{~g}$ ) for examining the binding activities of the drugs to inflammatory cells (Japan Slc Inc., Shizuoka, Japan). We used rats between 5 and 6 weeks old as a certain growing and adolescent rat for these studies. The animals were provided with food and water ad libitum, and were housed under controlled temperature $\left(21^{\circ} \mathrm{C}-24^{\circ} \mathrm{C}\right)$, humidity (45\% - 61\%), and lighting (lights on from 06:00 to 18:00) conditions. All animal procedures employed in this study were approved by the guidelines of the Animal Ethical 
Committee of Mitsubishi Tanabe Pharma Corporation.

\section{2. $\mathrm{PGE}_{2}$ Production by Rat Peritoneal Leukocytes}

The PGE 2 production activity was evaluated according to the procedure described in a previous report, with slight modification [8]. The Wistar rats were sacrificed by a bloodless procedure and the abdominal cavity of the rats was washed with $20 \mathrm{~mL}$ of ice-chilled Krebs-Ringer-bicarbonate solution containing $10 \mathrm{units} / \mathrm{mL}$ of heparin. The washings of the abdominal cavity were centrifuged at $200 \mathrm{~g}$ for $5 \mathrm{~min}$ at $4^{\circ} \mathrm{C}$. The obtained peritoneal cells were washed twice with Krebs-Ringer-bicarbonate solution containing bovine serum albumin $(100 \mu \mathrm{g} / \mathrm{mL})$. This peritoneal cell suspension at a volume of $900 \mu \mathrm{L}\left(4.5 \times 10^{6}\right.$ cells $\left./ \mathrm{mL}\right)$ and the drug (SFP, RFP and FP) solution at a volume of $50 \mu \mathrm{L}$ were added to a test tube, followed by the addition of $50 \mu \mathrm{L}$ of inactivated Bordetella pertussis suspension (Wako Pure Chemical Industries Ltd., Osaka, Japan, $4.5 \times 10^{9}$ bacteria/mL) as the reaction solution. After incubation of the reaction solution at $37^{\circ} \mathrm{C}$ for $20 \mathrm{~min}$, it was centrifuged at $460 \mathrm{~g}$ for $5 \mathrm{~min}$ at $4^{\circ} \mathrm{C}$. The supernatants were collected and the $\mathrm{PGE}_{2}$ levels were quantitated by the PGE 2 EIA system (GE Healthcare Life Sciences, Waukesha, WI, USA). SFP and RFP were obtained from Tokuhon Corporation (Saitama, Japan) and KNC Laboratories Co., Ltd. (Kobe, Japan), respectively. FP was obtained from Wako Pure Chemical Industries Ltd. (Osaka, Japan).

\subsection{Binding Activities of SFP and RFP to Polymorphonuclear Leukocytes (PMNs) and Erythrocytes}

To analyze the mechanism of stereoselective $\mathrm{PGE}_{2}$ inhibition of SFP and RFP in rat peritoneal leukocytes, we examined the binding properties of SFP and RFP to the PMNs and erythrocytes, which show differential expressions of the COX protein. PMNs were prepared according to the method described in a previous report [9]. Wistar rats were sacrificed by a bloodless procedure at approximately $16 \mathrm{~h}$ after intraperitoneal administration of $5 \%$ nutrose at $10 \mathrm{~mL} / \mathrm{rat}$, and the abdominal cavity of the rats was washed with $22 \mathrm{~mL}$ of Krebs-Ringer-bicarbonate solution to collect PMNs. The PMN cell suspension was filtered through cotton (PMNs, $3 \times 10^{7}$ cells $/ \mathrm{mL}$ ). Erythrocytes were prepared according to the procedure described in a previous report [10]. Wistar rats were anesthetized and blood samples were collected from the abdominal aorta into heparinized syringes. After the centrifugation of blood samples, the lower layer of the sample solutions containing the erythrocytes were collected and washed 3 times with Krebs-Ringer-bicarbonate solution $\left(1 \times 10^{9}\right.$ cells $\left./ \mathrm{mL}\right)$. For counting the PMNs and erythrocytes, an auto-erythrocyte counting device (MEK-5258 type, Nihon Kohden) was used.

After pre-incubation of $1.25 \mathrm{~mL}$ of the PMN or erythrocyte suspensions at $37^{\circ} \mathrm{C}$ for $3 \mathrm{~min}, 3 \mathrm{nM}$ of SFP or RFP solution was added to the cell suspension. Then, $0.25 \mathrm{~mL}$ portions of the sample solution were pipetted after 5, 15, 30 and $60 \mathrm{~min}$ of incubation, and the pipetted incubation mixtures were immediately centrifuged at $3000 \mathrm{rpm}$ for $5 \mathrm{~min}$ at $4^{\circ} \mathrm{C}$. The supernatants were collected and the drug concentrations were measured by highperformance liquid chromatography (HPLC). The protein concentrations in the PMN or erythrocyte suspensions were measured according to the procedure of Bradford [11]. The binding concentrations of the drugs to the cells were calculated using following formula. Binding drug concentration (nmol/mg protein) $=\left(C_{0}-C_{t} / P\right)$, where $C_{0}$ : Drug concentration in the control supernatant; $\mathrm{C}_{\mathrm{t}}$ : Drug concentration in the supernatant after incubation for $\mathrm{t}$ hour; P: protein content.

\subsection{In Vitro Skin Permeation Study}

To characterize the suitability of the drug for use in an NSAID patch, we tested the skin permeability of SFP, RFP and FP in YMP skin, which is used for prediction of drug permeability through human skin. The YMP skin (female pigs: approximately 5 months old) was commercially obtained (Charles River Japan Inc., Kanagawa, Japan), and the skin permeation was measured as follows. A two-chamber side-by-side diffusion cell was used. The excised skin was sandwiched between the two halves of the diffusion cell. The donor side was filled with the drug suspension (SFP, RFP, FP) in phosphate buffer (PBS) and the receiver side was filled with PBS. The whole cell was kept at $37^{\circ} \mathrm{C}$ and stirred using a magnetic stirrer. An aliquot of the receiver solution was collected as the sample at determined times (4, 6, 8, 10, 12 and $24 \mathrm{~h})$. The concentrations of SFP and RFP in the samples were determined by HPLC. The cumulative penetrating amounts $\left(\mathrm{Q}, \mu \mathrm{g} / \mathrm{cm}^{2}\right)$ versus time were plotted on a graph. The steady state permeation rate (Flux, $\mathrm{mg} / \mathrm{cm}^{2} / \mathrm{h}$ ) was subsequently calculated from a slope ob- 
tained by linear regression of the data from 6 to $12 \mathrm{~h}$ on the graph. Lag time was calculated from the $\mathrm{X}$-intercept obtained by elongation of the part of the steady state $(6-12 \mathrm{~h})$.

\subsection{Concentrations of SFP and RFP}

The LC-10A HPLC system (Shimadzu Corporation, Kyoto, Japan) with fluorescence detection was used for determination of the concentrations of SFP and RFP in the samples. In the binding study to the PMNs and the erythrocytes, samples were centrifuged at $4^{\circ} \mathrm{C}$ and $150 \mu \mathrm{L}$ of the supernatant added internal standard was injected into the HPLC system. In the skin permeation study, $20 \mu \mathrm{L}$ of samples were directly injected into the HPLC system without internal standard. Chromatographic separation was achieved using a YMC CHIRAL $\gamma$ CD BR $4.6 \times 250 \mathrm{~mm}$ column (YMC Co., Ltd., Kyoto, Japan) with $0.5 \mathrm{M}$ trimethylamine-acetic acid solution (pH 4.0)/acetonitrile (82:18) at a flow rate of $0.8 \mathrm{~mL} / \mathrm{min}$ and at $25^{\circ} \mathrm{C}$ or $30^{\circ} \mathrm{C}$ of column temperature. The absorbance values of the analytes were detected at $262 \mathrm{~nm}$ (excitation wavelength) and $313 \mathrm{~nm}$ (emission wavelength). The concentration of FP was calculated by summation of the concentrations of SFP and RFP.

\subsection{Data Analysis}

The results are expressed as mean \pm SD, or as the means with the $95 \%$ confidence interval. The $\mathrm{IC}_{50}$ values for $\mathrm{PGE}_{2}$ inhibition were calculated from the linear regression of the inhibition rate. The differences in the binding activities of SFP and RFP to the PMNs and erythrocytes were analyzed by repeated-measures ANOVA, followed by the t-test. The differences in the Flux and the lag time among the drugs in the skin permeation study were analyzed by the Tukey method.

\section{Results}

\subsection{Effect of SFP, RFP and FP on $\mathrm{PGE}_{2}$ Production by Peritoneal Leukocytes}

SFP, RFP and FP showed concentration-dependent inhibition of $\mathrm{PGE}_{2}$ production from peritoneal leukocytes stimulated with bacterial suspension. The IC50 values were SFP, $14 \mathrm{nM}$; FP, $52 \mathrm{nM}$ and RFP, 17,000 nM, respectively, as summarized in Table 1. The SFP showed potent inhibition on COX activity, and was 1000-fold more potent than the RFP in inhibiting COX activity.

\subsection{Binding Activity of SFP and RFP to PMNs and Erythrocytes}

The time-courses of the binding activity of SFP and RFP to PMNs and erythrocytes are shown in Figure 1. The typical HPLC chromatograms are presented in Figure 2. Significant and rapid increase of the binding concentration of SFP was observed until 5 min after the start of incubation, and a steady state was maintained from 5 to $60 \mathrm{~min}$ of incubation. The binding concentration of SFP after $5 \mathrm{~min}$ incubation was approximately $0.37 \mathrm{nmol} / \mathrm{mg}$ protein. In contrast, the binding concentration of RFP showed a slight and transient increase until 5 min after the start of incubation $(0.04 \mathrm{nmol} / \mathrm{mg}$ protein), gradually decreasing from $5 \mathrm{~min}$ to $60 \mathrm{~min}$ of incubation. In the case of erythrocytes, which do not express COX or produce $\mathrm{PGE}_{2}$, scarce binding of SFP to the cells was observed. RFP showed significantly higher binding activity to erythrocytes as compared to SFP. The binding concentrations of SFP and RFP to the erythrocytes were 0.02 and $0.04 \mathrm{nmol} / \mathrm{mg}$ protein, respectively.

Table 1. Inhibitory effect of SFP, FP and RFP on the production of prostaglandin $\mathrm{E}_{2}$ by rat peritoneal leukocytes.

\begin{tabular}{cc}
\hline Drug & $\mathrm{IC}_{50}(\mathrm{~mol} / \mathrm{L})[95 \% \mathrm{CI}]$ \\
\hline $\mathrm{S}(+)$-flurbiprofen & $1.4 \times 10^{-8}\left[0.61-3.1 \times 10^{-8}\right]$ \\
Flurbiprofen & $5.2 \times 10^{-8}\left[2.3-12 \times 10^{-8}\right]$ \\
$\mathrm{R}(-)$-flurbiprofen & $1.7 \times 10^{-5}\left[0.77-4.2 \times 10^{-5}\right]$ \\
\hline
\end{tabular}

Data are expressed as the mean (95 percent confidence interval) obtained from 3 individual determinations. The $\mathrm{IC}_{50}$ values were calculated as the by linear regression from the inhibition rate. 

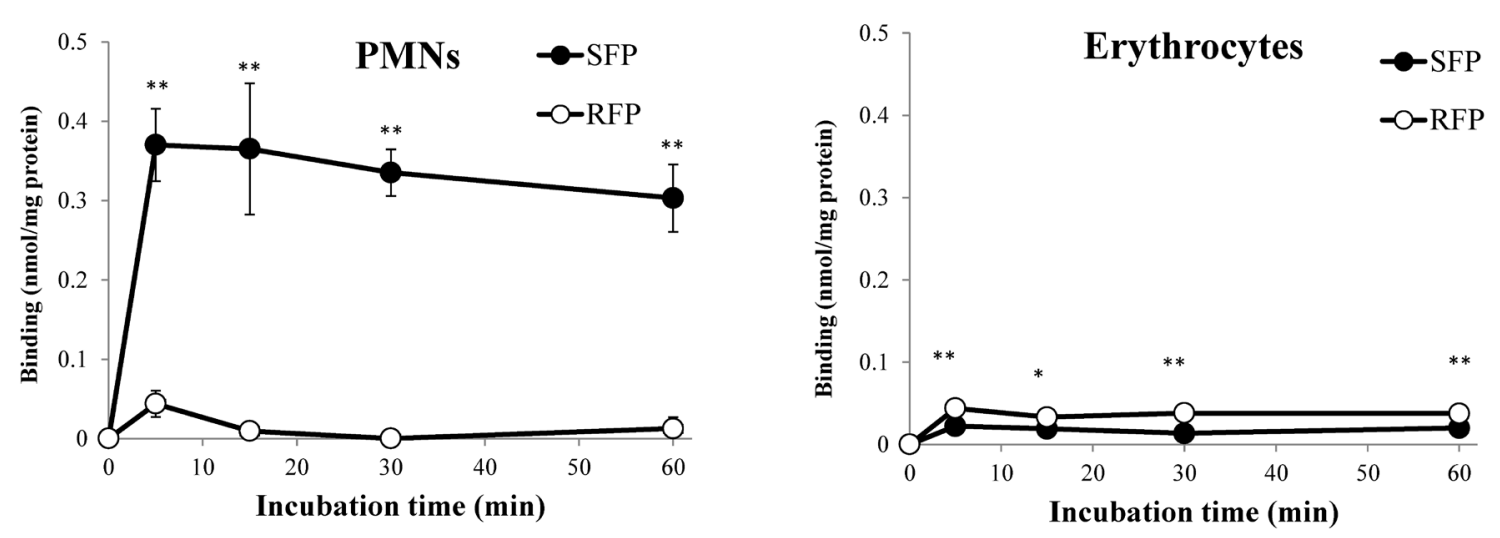

Figure 1. Binding property of the test drugs to PMNs or erythrocytes. After incubation of SFP (3 nM) or RFP (3 nM) with PMNs $\left(3 \times 10^{7}\right.$ cells $\left./ \mathrm{mL}\right)$ and erythrocytes $\left(1 \times 10^{9}\right.$ cells $\left./ \mathrm{mL}\right)$, the concentration of the drugs in the culture medium were measured by HPLC. The binding affinity of the drugs to the cells was calculated from the drug concentration in the supernatant of the concentrations in the cell supernatants after each hour of incubation with the test drug. Each point represents the mean \pm SD $(n=3$ or 4$)$. ${ }^{* *}: \mathrm{p}<0.01 . *: \mathrm{p}<0.05$; Significant difference from RFP (t-test; repeated-measures ANOVA).
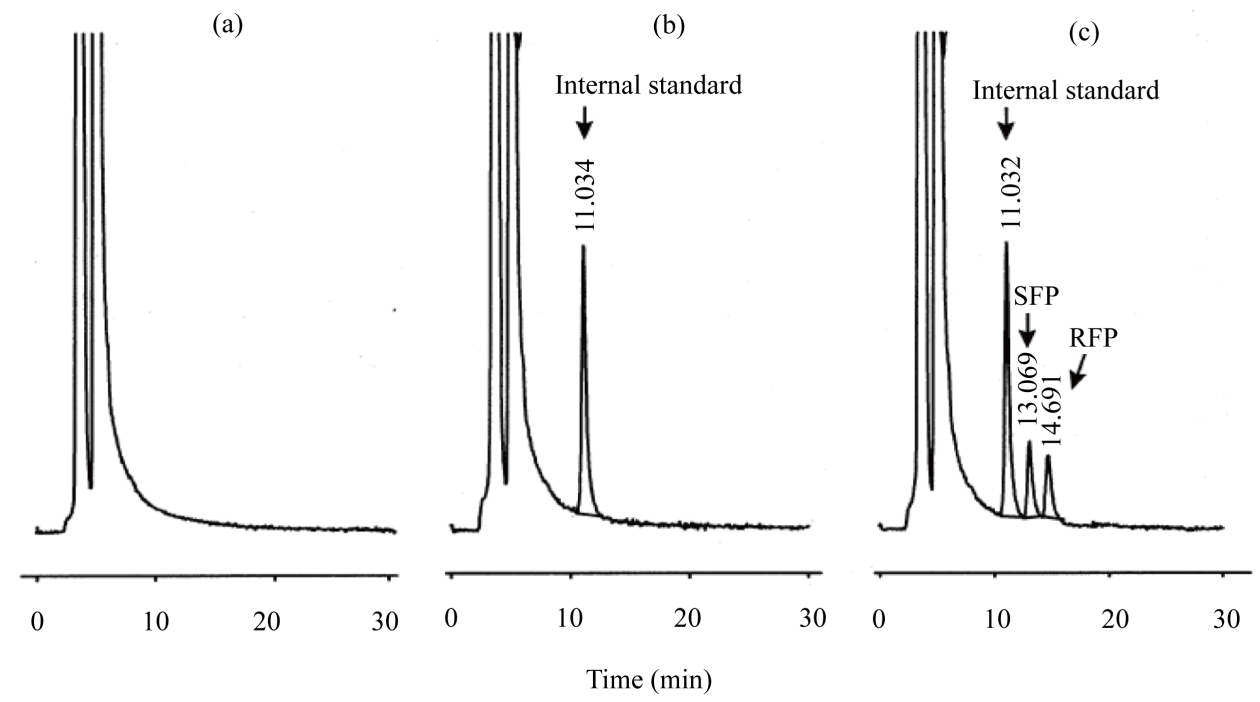

standard, (c) Internal standard, SFP and RFP.

\subsection{Skin Permeability Profile of SFP, RFP and FP in the YMP Model}

The changes in the values of Q of SFP, RFP and FP evaluated using the YMP model are shown in Figure 3 . The $\mathrm{Q}$ value increased in a time-dependent manner for each of the drugs. The rank order of the $\mathrm{Q}$ values for the drugs was SFP $>$ RFP $>$ FP. Table 2 shows the Flux and lag time. The Flux of SFP $\left(4.89 \mu \mathrm{g} / \mathrm{cm}^{2} / \mathrm{h}\right)$ and RFP $\left(4.16 \mu \mathrm{g} / \mathrm{cm}^{2} / \mathrm{h}\right)$ were significantly higher than that of FP $\left(1.55 \mu \mathrm{g} / \mathrm{cm}^{2} / \mathrm{h}\right)$. The lag time of SFP $(2.86 \mathrm{~h})$ was significantly shorter than that of FP (5.20 h).

\section{Discussion}

We previously showed that SFP potently inhibits human COX-1 and COX-2, SFPP exhibits good skin absorbability and has been shown to inhibit inflammatory pain in the rat AIA model [6]. In this study, we tested the following properties of SFP as compared to those of an FP racemic mixture and the RFP enantiomer: 1) stereospecificity of the $\mathrm{PGE}_{2}$ inhibitory activity in inflammatory leukocytes, 2) transfer property across cells, and 3) in vitro skin permeability in the YMP model. 


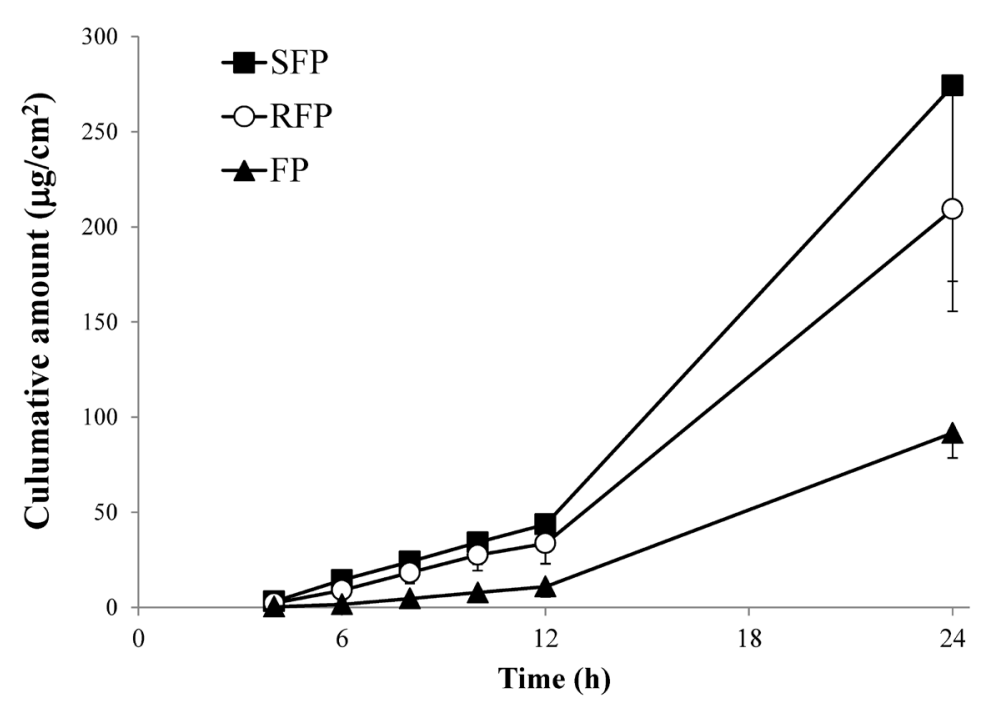

Figure 3. Skin permeability profiles of SFP, RFP and FP in the YMP model. The Q values of SFP, RFP and FP were evaluated using YMP skin. The solution on the receiver side of the two-chamber side-by-side diffusion cell was sequentially collected and the concentrations of the drugs in these solution samples were determined by HPLC. Data are expressed as mean-SD $(n=5)$. Q: cumulative penetrating amounts.

Table 2. Flux and lag time of SFP, RFP and FP in miniature pig skin.

\begin{tabular}{ccc}
\hline Drug & Flux $\left(\mu \mathrm{g} / \mathrm{cm}^{2} / \mathrm{h}\right)$ & Lag time $(\mathrm{h})$ \\
\hline $\mathrm{S}(+)$-flurbiprofen & $4.89 \pm 2.32^{* *}$ & $2.86 \pm 1.42^{*}$ \\
$\mathrm{R}(-)$-flurbiprofen & $4.16 \pm 0.25^{*}$ & $3.66 \pm 1.36$ \\
Flurbiprofen & $1.55 \pm 0.61$ & $5.20 \pm 0.81$
\end{tabular}

Each value represents the mean \pm SD of 5 individual determinations. ${ }^{*} \mathrm{p}<0.05,{ }^{* *} \mathrm{p}<0.01$; significantly different from FP (Tukey’s multiple comparison test).

The results revealed that first of all, SFP potently inhibited $\mathrm{PGE}_{2}$ production from peritoneal leukocytes stimulated with a bacterial suspension; its inhibitory activity against $\mathrm{PGE}_{2}$ production in a rat intact cell model was a 1000-fold more potent than that of RFP and also exhibited stereoselectivity. In human polymorphonuclear cell models, SFP was shown to potently inhibit PG production $\left(\mathrm{IC}_{50}=2.7 \mathrm{nM}\right.$ for SFP and $400 \mathrm{nM}$ for SFP, respectively; RFP/SFP inhibitory ratio = 148) [5]. Our results suggested that the inhibitory activity of SFP in human polymorphonuclear cells was nearly as effective as the inhibitory activity of SFP in the rat peritoneal leukocytes. In a previous study, we demonstrated that a newly developed NSAID patch, the S-flurbiprofen plaster (SFPP), containing the (S)-enantiomer of flurbiprofen, rapidly inhibited inflammatory pain in the rat AIA model. The potent inhibitory activity of SFP on $\mathrm{PGE}_{2}$ production in this study suggested that the in vivo efficacy of SFPP could be mediated by inhibition on $\mathrm{PGE}_{2}$ production from rat peritoneal leukocytes.

$\mathrm{PGE}_{2}$ formation is catalyzed by COX, which exists in two isoforms (COX-1 and COX-2). COX-1 appears to be expressed constitutively under physiologic conditions. In contrast, COX-2 expression is induced by cytokines, or endotoxin in vitro. We previously reported that SFP exhibits comparably potent inhibitory activity against human COX-1 and COX-2, suggesting that the inhibition of PGE $_{2}$ production by SFP in leukocytes could be attributable to its inhibitory activity on both the COX isoforms.

The results of the present study also showed that SFP exerted superior binding activity to the PMNs as compared to the RFP enantiomer. While PMNs are the main component of the immune defense system involved in the degradation of microorganisms, the PMNs in inflammatory lesions also produce several inflammatory mediators, including $\mathrm{PGE}_{2}$. The favorable cellular binding activity of SFP suggests that the anti-inflammatory properties of SFP are superior to those of RFP.

This is the first study to examine the difference in the binding potency to PMNs between $\mathrm{S}$ and $\mathrm{R}$ enantiomers, 
and to show the superior binding potency of the S enantiomer (SFP) as compared to that of the R enantiomer (RFP). There are only a few reports on the binding affinities of other NSAIDs to PMNs. Raghoebar reported that indomethacin was rapidly taken up by the cells, reaching a steady state after 30 min [12], which is consistent with the rapid cell binding of SFP observed in our study. However, it remained unclear in our binding study as to whether the SFP was incorporated into the cells or not. However, the localization of the COX enzymes in the ER and nuclear envelope might suggest that SFP was indeed taken up by the cells and showed favorable cellular transfer potency. On the other hand, SFP showed scarce binding affinity for erythrocytes, but RFP significantly increased the binding to erythrocytes. Erythrocytes has not nuclear envelope in which COX enzyme mainly exist, suggesting the reason that SFP does not bind to erythrocytes, yet the mechanism that RFP significantly increased the binding to erythrocytes remained unknown. Further study is needed to qualify the character underlying this phenomenon.

The skin permeabilities of SFP, RFP and FP were also examined in the YMP skin model. The number of hairs on the YMP skin is similar to that on human skin, and the total lipid content is also similar to that in the human epidermis [13] [14]. In addition, the thicknesses of the stratum corneum, epidermis and dermis of YMP skin are similar to those of human skin. Besides these similarities to human skin, because of the reproducibility of the Flux of drugs through the YMP skin, YMP skin has been used as an in vitro model of animal skin [15] [16]. In this study, the superior skin permeability profile, including the favorable values of Q, Flux and lag time, of SFP as compared to FP in the YMP skin indicates the favorable physiological properties of SFP for percutaneous absorption. On the contrary, in a previous study carried out using hairless rat skin, the skin permeability profile of RFP was shown to be significantly superior to that of SFP [17]. This discrepancy could possibly be explained by the differences in the skin characteristics between YMP and rats.

Differences in the skin permeability between racemates and enantiomers have been reported for other chiral drugs. It was demonstrated in one study that the skin permeability, in the mouse skin, of S-ketoprofen was superior to that of ketoprofenracemate [18]. In another study, S-ketorolac was demonstrated to show superior permeation as compared to ketorolac racemate across human skin [19]. The reasons for these differences among the $\mathrm{S}$ and $\mathrm{R}$ enantiomers and racemates remain unknown, and further studies in the future are required to elucidate the underlying mechanisms.

In this study, SFP exerted potent inhibitory activity on $\mathrm{PGE}_{2}$ production, and also showed superior binding to PMNs and superior skin permeability, as compared to FP and/or RFP. These results validate the favorable characteristics of SFP as an active ingredient of an NSAID patch.

\section{Conflict of Interest}

Y. Toda, M. Sugimoto, H. Endo, S. Kaku, and N. Otsuka are employees of Taisho Pharmaceutical Co., Ltd. M. Kamezawa, I. Yamada are employees of Mitsubishi Tanabe Pharma Corporation. S. Kawabata is an employee of Tokuhon Corporation. H. Matsumoto receives consulting fees from Taisho Pharmaceutical Co., Ltd.

\section{References}

[1] Narumiya, S., Sugimoto, Y. and Ushikubi, F. (1999) Prostanoid Receptors: Structures, Properties, and Functions. Physiological Reviews, 79, 1193-1226.

[2] Rannou, F., Pelletier, J.P. and Martel-Pelletier, J. (2016) Efficacy and Safety of Topical NSAIDs in the Management of Osteoarthritis: Evidence from Real-Life Setting Trials and Surveys. Seminars in Arthritis and Rheumatism, 45, S18S21. http://dx.doi.org/10.1016/j.semarthrit.2015.11.007

[3] Mason, L., Moore, R.A., Edwards, J.E., Derry, S. and McQuay, H.J. (2004) Topical NSAIDs for Chronic Musculoskeletal Pain: Systematic Review and Meta-Analysis. BMC Musculoskeletal Disorders, 5, 28. http://dx.doi.org/10.1186/1471-2474-5-28

[4] Peskar, B.M., Kluge, S., Peskar, B.A., Soglowek, S.M. and Brune, K. (1991) Effects of Pure Enantiomers of Flurbiprofen in Comparison to Racemic Flurbiprofen on Eicosanoid Release from Various Rat Organs ex Vivo. Prostaglandins, 42, 515-531. http://dx.doi.org/10.1016/0090-6980(91)90014-7

[5] Carabaza, A., Cabré, F., Rotllan, E., Gómez, M., Gutiérrez, M., García, M.L. and Mauleón, D. (1996) Stereoselective Inhibition of Inducible Cyclooxygenase by Chiral Nonsteroidal Antiinflammatory Drugs. The Journal of Clinical Pharmacology, 36, 505-512. http://dx.doi.org/10.1002/j.1552-4604.1996.tb05040.X

[6] Sugimoto, M., Toda, Y., Hori, M., Mitani, A., Ichihara, T., Sekine, S., Hirose, T., Endo, H., Futaki, N., Kaku, S., Otsuka, N. and Matsumoto, H. (2016) Analgesic Effect of the Newly Developed S(+)-Flurbiprofen Plaster (SFPP) on Inflammatory Pain in a Rat Adjuvant-Induced Arthritis Model. Drug Development Research, 77, 20-28. 
http://dx.doi.org/10.1002/ddr.21288

[7] Yataba, I., Otsuka, N., Matsushita, I., Kamezawa, M., Yamada, I., Sasaki, S., Uebaba, K., Matsumoto, H. and Hoshino, Y. (2016) Plasma Pharmacokinetics and Synovial Concentrations of S-Flurbiprofen Plaster in Humans. European Journal of Clinical Pharmacology, 72, 53-59. http://dx.doi.org/10.1007/s00228-015-1960-6

[8] Di Rosa, M. and Persico, P. (1979) Mechanism of Inhibition of Prostaglandin Biosynthesis by Hydrocortisone in Rat Leucocytes. British Journal of Pharmacology, 66, 161-163. http://dx.doi.org/10.1111/j.1476-5381.1979.tb13659.x

[9] Smith, R.J. (1978) Nonsteroid Anti-Inflammatory Agents: Regulators of the Phagocytic Secretion of Lysosomal Enzymes from Guinea-Pig Neutrophils. Journal of Pharmacology and Experimental Therapeutics, 207, 618-629.

[10] Matsumoto, Y., Ohsako, M. and Noda, F. (1989) Transport of Drugs through Human Erythrocyte Membrane in Vitro. Yakuzaigaku, 49, 59-63.

[11] Bradford, M.M. (1976) Rapid and Sensitive Method for the Quantitation of Microgram Quantities of Protein Utilizing the Principle of Protein-Dye Binding. Analytical Biochemistry, 72, 248-254. http://dx.doi.org/10.1016/0003-2697(76)90527-3

[12] Raghoebar, M., Tiemessen, H.L., van den Berg, W.B. and van Ginneken, C.A. (1989) Modes of Association of Indometacin with Human Polymorphonuclear Leucocytes. Pharmacology, 39, 350-361. http://dx.doi.org/10.1159/000138622

[13] Fujii, M., Yamanouchi, S., Hori, N., Iwanaga, N., Kawaguchi, N. and Matsumoto, M. (1997) Evaluation of Yucatan Micropig Skin for Use as an in Vitro Model for Skin Permeation Study. Biological and Pharmaceutical Bulletin, 20, 249-254. http://dx.doi.org/10.1248/bpb.20.249

[14] Kurihara-Bergstrom, T., Woodworth, M., Feisullin, S. and Beall, P. (1986) Characterization of the Yucatan Miniature Pig Skin and Small Intestine for Pharmaceutical Applications. Laboratory Animal Science, 36, 396-399.

[15] Roberts, M.E. and Mueller, K.R. (1990) Comparisons of in Vitro Nitroglycerin (TNG) Flux across Yucatan Pig, Hairless Mouse, and Human Skins. Pharmaceutical Research, 7, 673-676. http://dx.doi.org/10.1023/A:1015842916969

[16] Takeuchi, H., Ishida, M., Furuya, A., Todo, H., Urano, H. and Sugibayashi, K. (2012) Influence of Skin Thickness on the in Vitro Permeabilities of Drugs through Sprague-Dawley Rat or Yucatan Micropig Skin. Biological and Pharmaceutical Bulletin, 35, 192-202. http://dx.doi.org/10.1248/bpb.35.192

[17] Valentová, J., Bauerová, K., Farah, L. and Devínsky, F. (2010) Does Stereochemistry Influence Transdermal Permeation of Flurbiprofen through the Rat Skin? Archives of Dermatological Research, 302, 635-638. http://dx.doi.org/10.1007/s00403-010-1063-2

[18] Kommuru, T.R., Khan, M.A. and Reddy, I.K. (1998) Racemate and Enantiomers of Ketoprofen: Phasediagram, Thermodynamic Studies, Skin Permeability, and Use of Chiral Permeation Enhancers. Journal of Pharmaceutical Sciences, 87, 833-840. http://dx.doi.org/10.1021/js9704644

[19] Roy, S.D., Chatterjee, D.J., Manoukian, E. and Divor, A. (1995) Permeability of Pure Enantiomers of Ketorolac through Human Cadaver Skin. Journal of Pharmaceutical Sciences, 84, 987-990. http://dx.doi.org/10.1002/jps.2600840815

\section{Submit or recommend next manuscript to SCIRP and we will provide best service for you:}

Accepting pre-submission inquiries through Email, Facebook, LinkedIn, Twitter, etc.

A wide selection of journals (inclusive of 9 subjects, more than 200 journals)

Providing 24-hour high-quality service

User-friendly online submission system

Fair and swift peer-review system

Efficient typesetting and proofreading procedure

Display of the result of downloads and visits, as well as the number of cited articles

Maximum dissemination of your research work

Submit your manuscript at: http://papersubmission.scirp.org/ 